\title{
Habitat restoration benefits wild bees: A meta-analysis
}

\author{
Rebecca K. Tonietto ${ }^{1,2,3}$ (D) | Daniel J. Larkin ${ }^{3,4}$
}

${ }^{1}$ Department of Biology, University of Michigan-Flint, Flint, MI, USA

${ }^{2}$ Plant Biology and Conservation, Northwestern University, Evanston, IL, USA

${ }^{3}$ Plant Science and Conservation, Chicago Botanic Garden, Glencoe, IL, USA

${ }^{4}$ Department of Fisheries, Wildlife, and Conservation Biology, University of Minnesota, St. Paul, MN, USA

\section{Correspondence}

Rebecca K. Tonietto

Email: tonietto@umflint.edu

\section{Funding information}

Prairie Biotic Research Fund; Northwestern University; the Chicago Botanic Garden; Garden Club of America, Fellowship in Ecological Restoration

Handling Editor: Sarah Diamond

\section{Abstract}

1. Pollinator conservation is of increasing interest in the light of managed honeybee (Apis mellifera) declines, and declines in some species of wild bees. Much work has gone into understanding the effects of habitat enhancements in agricultural systems on wild bee abundance, richness and pollination services. However, the effects of ecological restoration targeting "natural" ecological endpoints (e.g. restoring former agricultural fields to historic vegetation types or improving degraded natural lands) on wild bees have received relatively little attention, despite their potential importance for countering habitat loss.

2. We conducted a meta-analysis to evaluate the effects of ecological restoration on wild bee abundance and richness, focusing on unmanaged bee communities in lands restored and managed to increase habitat availability and quality. Specifically, we assessed bee abundance and/or richness across studies comparing restored vs. unrestored treatments and studies investigating effects of specific habitat restoration techniques, such as burning, grazing, invasive plant removal and seeding.

3. We analysed 28 studies that met our selection criteria: these represented 11 habitat types and 7 restoration techniques. Nearly all restorations associated with these studies were performed without explicit consideration of habitat needs for bees or other pollinators. The majority of restorations targeted plant community goals, which could potentially have ancillary benefits for bees.

4. Restoration had overall positive effects on wild bee abundance and richness across multiple habitat types. Specific restoration actions, tested independently, also tended to have positive effects on wild bee richness and abundance.

5. Synthesis and applications. We found strong evidence that ecological restoration advances wild bee conservation. This is important given that habitat loss is recognized as a leading factor in pollinator decline. Pollinator responses to land management are rarely evaluated in non-agricultural settings and so support for wild bees may be an underappreciated benefit of botanically focused management. Future restoration projects that explicitly consider the needs of wild bees could be more effective at providing nesting, foraging and other habitat resources. We encourage land managers to design and evaluate restoration projects with the habitat needs of wild bee species in mind.

\section{KEYWORDS}

abundance, bees, burning, conservation, grazing, habitat, land management, pollinators, restoration, species richness 


\section{1 | INTRODUCTION}

Bees are arguably the most important pollinators world-wide (Buchmann \& Nabhan, 1996), responsible for the majority of pollination in agricultural and natural systems (National Research Council, 2007). Recent declines in bee species, and their importance as ecosystem service providers, have brought bees to the forefront of conservation efforts. For bee species with documented losses and in geographic regions with historic bee community data available, habitat loss is a frequently cited factor in bee declines (Cameron et al., 2011; Grixti, Wong, Cameron, \& Favret, 2009; Winfree, Aguilar, Vasquez, LeBuhn, $\&$ Aizen, 2009). To combat habitat loss, there has been considerable research evaluating the effectiveness of habitat enhancements for wild bees in otherwise developed landscapes, such as agricultural systems or cities (Dicks, Showler, \& Sutherland, 2010; Grixti et al., 2009; Hall et al., 2016; Maclvor \& Packer, 2015; Pawelek, Frankie, Thorp, \& Przybyiski, 2009; Shepherd, Buchmann, Vaughn, \& Black, 2003; Vaughan \& Skinner, 2008).

To date, most bee conservation efforts have focused on providing resources for wild bees (e.g. nesting and foraging resources) within otherwise human-dominated land uses (Batáry et al., 2010; Shepherd et al., 2003). In a recent meta-analysis, habitat enhancements for wild bees were found to be effective in agricultural systems (Scheper et al., 2013). For example, addition of native hedgerows or planting of wildflowers in field margins can provide consistent foraging opportunities, leading to greater wild bee diversity and abundance (Haaland, Naisbit, \& Bersier, 2011; Pywell et al., 2005, 2012). Likewise, installing nesting boxes or maintaining patches of bare, untilled ground have been found to provide nesting habitat (Dicks et al., 2010; Severns, 2004; Wesserling \& Tscharntke, 1995). In residential and urban areas, similar habitat enhancements can provide nesting and foraging resources for wild bees (Shepherd et al., 2003; but see Maclvor \& Packer, 2015). These enhancements have led to greater bee abundance and diversity relative to unmanipulated control sites in city parks and residential neighbourhoods (Frankie et al., 2009; Hernandez, Frankie, \& Thorp, 2009; Pawelek et al., 2009), yet the extent to which habitat enhancements provide resources for a functionally diverse suite of wild bees remains uncertain (Woodcock, Collin Harrower, et al., 2014).

On a larger scale, ecological restoration of undeveloped lands (e.g. degraded natural areas or restoration of former working lands, such as agricultural fields, back to pre-settlement habitats) may be an effective conservation tool to counter the effects of habitat loss on wild bees. Through restoration, practitioners assist the recovery of an ecosystem that has been degraded, damaged or destroyed (SER, 2004). Historically, habitat restoration has focused on plant community outcomes, and restoration management techniques frequently involve direct manipulation of the plant community (Young, 2000). Typical restoration actions include removal of invasive plant species, seeding and planting of native flora, reinstating historic fire regimes, reintroducing grazers and other regionally habitat-specific management actions.

Theoretically, restoration could be a "tide that raises all ships," improving habitat quality by directly altering plant communities. For example, vegetation dominated by a single invasive plant species provides little diversity in floral resources or bloom times, limiting the portfolio of bees that can be supported (M'Gonigle, Williams, Lonsdorf, \& Kremen, 2016). In such cases, increased plant diversity associated with invasive species management and subsequent restoration of a desirable botanical community could increase foraging opportunities for bees. These actions could lead to increases in bee abundance and richness, similar to habitat augmentations in agricultural areas (Scheper et al., 2013). Unlike small-scale enhancements of otherwise developed sites, restoration of natural areas can also return larger areas of contiguous habitat for native bees, returning landscapelevel and metacommunity processes (Montoya, Rogers, \& Memmott, 2012).

However, there is also potential for actions associated with restoration to act as disturbances to wild bees (Moretti, de Bello, Roberts, \& Potts, 2009; Williams et al., 2010). For example, removal of invasive species and burning or mowing without immediate replacement of mature plants may reduce foraging opportunities available to bees. Prescribed burning is commonly used in restoration to alter habitat structure and clear invasive or undesired vegetation; early in a restoration project, fire frequency may exceed that of the historic burn cycle (Packard \& Mutel, 1997). While burning could reveal more bare ground for soil nesters through removal of herbaceous litter, burning also removes standing dead material, such as the pithy stems and dead wood that many species require for nests (Michener, 2000). Burning and other disturbances are likely to differentially affect bees representing different nesting guilds, or even those of similar guilds found across different habitats (Moretti et al., 2009).

We conducted a meta-analysis to evaluate the overall impact of habitat restoration on wild bees, and the relative impact of specific management techniques (i.e. burning, grazing, overall restoration, ecological compensation meadows, invasive plant removal, mowing and seeding). Through meta-analysis we could calculate the relative and overall effect sizes of each restoration action and for restoration overall, while incorporating study size and replication into the strength of each response. We considered wild bee richness and/or abundance as responses and restricted our analysis to restorations targeting "natural" endpoints, e.g. grasslands or forests, but not anthropogenic or novel habitats like farms, housing developments or urban gardens. We retained studies of ecological compensation meadows, which are large-scale (i.e. multiple hectare) efforts to convert land used for hay production or pasturing to closer approximations of wild habitats. While these lands have an agricultural component, we considered them more comparable to grassland restorations than to crop production systems, as livestock grazing is a recognized tool for restoring grasslands in both Europe and North America (Dostálek \& Frantík, 2008; Hayes \& Holl, 2003).

We hypothesized that (1) habitat restoration would have generally positive effects on wild bee abundance and richness, (2) overall restoration would have a greater positive impact on wild bee abundance or richness than any one restoration action tested independently and (3) some specific restoration actions would function as disturbances, with negative effects on bee abundance or richness. 


\section{2 | MATERIALS AND METHODS}

\section{1 | Literature search}

To identify relevant studies, we searched Web of Science (Clarviate Analytics, 2015) using the following term combinations "bee AND (restor* OR habitat manag* OR habitat enhanc*)" with topic filters of "ecology" and "biodiversity conservation" on 6 December 2016. This search yielded 412 papers.

From this point, we individually examined studies and excluded those that took place within production agricultural settings (e.g. pollinator-friendly hedgerows around tomato fields) or focused on managed bees such as honeybees (Apis mellifera). We included studies that evaluated the effects of restoration overall (e.g. restored vs. unrestored comparisons) and studies of specific management actions frequently implemented in restoration (e.g. mowing, grazing and burning) that took place in degraded lands and former agricultural lands that were converted to pre-settlement conditions. We did not evaluate the effects of habitat remediation in lands that had been structurally transformed and/or polluted by human activities (e.g. strip mines, landfills or quarries). After identifying a total of 38 papers that met our criteria, we searched within the references in these papers for additional suitable studies. This yielded an additional nine papers, for a total of 47 .

\section{2 | Calculation of effect sizes}

Of the 47 studies, 28 contained data suitable for analysis, i.e. bee abundance and/or species richness were reported before and after restoration treatments or compared between restored vs. unrestored treatments in the article itself, in supplemental information or in communications with the authors (see Table S1). For the 19 excluded studies, data were not reported in a way that allowed us to calculate bee richness or abundance (e.g. authors reported total number of insects and insect species) and raw data were either unavailable or did not provide the necessary information (e.g. only insect counts were reported, not bees specifically). From the final 28 studies, we extracted a total of 70 data points for inclusion in the metaanalyses. For studies with multiple categorical treatments, we extracted multiple data points comparing each test variable (e.g. low-intensity grazing and high-intensity grazing) to the control or reference condition, as described in Koricheva, Gurecitch, and Mengersen (2013). For 14 papers, both wild bee abundance and richness were reported as response variables to restoration or management actions.

We calculated Hedge's $d$, an unbiased standardized mean difference corrected for small sample size, which is suitable for metaanalyses with few studies (Hedges \& Olkin, 1985; Koricheva et al., 2013). The effect size $d$ can be interpreted here as the inversevariance-weighted difference in abundance or richness of bees between restored and unrestored or reference conditions, measured in units of standard deviation. Large effect sizes can result from a large difference in mean bee abundance or diversity between treatments or from a small estimate of the pooled variance between treatments.

Whenever possible, we calculated effect size based on reported sample size, mean and standard deviation values of bee abundance or richness for each treatment (Koricheva et al., 2013). If data were not available, we emailed the corresponding author requesting these data. For studies where the author did not respond or necessary data were not available, we calculated an effect size based on a reported $F$-test or using mean and SD values extracted from figures using Web Plot Digitizer (Rohatgi, 2015). For studies with a continuous design (e.g. bee response to grazing intensity), we ran a Fischer's $z$ transformation on the correlation coefficient $r$ to calculate an effect size and then converted this value to Hedge's $d$ using the metafor package (Viechtbauer, 2010) in R version 3.3.3 (R Development Core Team, 2015).

In our calculations of Hedge's $d$ we were not able to account forvariance arising from measurement error in the underlying studies. Measurement error could arise from factors such as misidentification of specimens, differences in identification skill or data-entry errors. As articles included in this meta-analysis did not report measurement errors, we were unable to perform study-level corrections or attempt to calculate an average error correction term. That said, ecologists do increasingly attempt to estimate measurement error, as reviewed by Morrison (2016), and its incorporation into ecological meta-analyses may become more common-as is the case, for example, in medical research (Schmidt \& Hunter, 2015).

\subsection{Analyses of effect size and heterogeneity}

All statistical analyses were performed in $R$ version 3.3.3 ( $R$ Development Core Team, 2015) using the package metaphor (Viechtbauer, 2010). For each response variable (bee abundance or richness), we created a random effects model with study and restoration action (burning, grazing, overall restoration, ecological compensation meadows, invasive plant removal, mowing and seeding) as random factors to account for non-independence between different treatments within the same study or of responses to the same treatment across studies. Models were fitted using restricted maximumlikelihood estimation (Koricheva et al., 2013).

We grouped studies by restoration action (Table 1 ) and constructed models within each of these categories with study as a random factor to account for non-independence. To determine if effect sizes across studies were similar, we calculated heterogeneity $(Q)$ within each restoration category and for all studies combined.

\subsection{Publication bias and sensitivity analyses}

To explore the possibility of publication bias, we constructed funnel plots-scatter plots of effect sizes against a measure of their varianceto determine if reported studies were unbalanced, as recommended by Koricheva et al. (2013). A publication bias towards significant results would create an asymmetrical funnel, typically missing small studies with non-significant effects. Having found funnel asymmetry, we used trim-and-fill plots to estimate "missing" studies. We then updated mean effect sizes with imputed missing studies, and compared original and updated mean effect sizes using $t$ tests. Finally, we calculated Rosenberg's weighted fail-safe number (Rosenberg, 2005), an estimate of the number of unpublished studies with an effect size of zero that would need to be added to make the observed effect size non-significant $(p>.05)$. 
TABLE 1 Heterogeneity of effect sizes (Q) between studies within restoration categories for the response variables wild bee abundance and species richness

\begin{tabular}{|c|c|c|c|c|c|c|}
\hline \multirow[b]{2}{*}{ Restoration category } & \multicolumn{3}{|c|}{ Abundance } & \multicolumn{3}{|c|}{ Richness } \\
\hline & $d f$ & $Q$ & $p$ & $d f$ & $Q$ & $p$ \\
\hline Restoration & 4 & 3.87 & .42 & 4 & 4.89 & .28 \\
\hline $\begin{array}{l}\text { Ecological compensation } \\
\text { meadows }\end{array}$ & & & & 3 & 19.02 & .0003 \\
\hline Burning & 6 & 10.98 & .08 & 6 & 8.26 & .21 \\
\hline Grazing & 12 & 29.32 & .003 & 4 & 11.29 & .02 \\
\hline Invasive plant removal & 4 & 2.89 & .57 & 4 & 32.81 & $<.0001$ \\
\hline Mowing & 5 & 537.78 & $<.0001$ & 3 & 7.19 & .06 \\
\hline Seeding & 2 & 1.94 & .37 & & & \\
\hline
\end{tabular}

\section{3 | RESULTS}

Overall, restoration in general and specific restoration actions had positive effects on bee abundance $(d=1.49,95 \% \mathrm{Cl} 0.92-2.06$, $p<.0001$, Figure 1$)$ and richness $(d=1.01,95 \% \mathrm{Cl} 0.65-1.38$, $p<.0001$, Figure 2). Effects of restoration and management differed by study and were heterogeneous for bee abundance $(Q=637.50$, $d f=38, p<.0001$, Figure 1$)$ and richness $(Q=117.88, \quad d f=31$, $p<.0001$, Figure 2).

Of the 70 data points identified, 39 reported wild bee abundance and 31 reported wild bee richness (see Table S1). The majority of studies were conducted in Europe $(n=17)$ and North America $(n=10$ United States, $n=1$ Canada) with two additional studies conducted, at least partially, in Israel. These included studies that evaluated the effects of restoration in general and creation of ecological compensation meadows, as well as mowing, burning, grazing, invasive plant removal and seeding (Table S1).

\section{1 | Mean effect sizes of restoration and heterogeneity among studies: Bee abundance}

All restoration categories had positive mean effect sizes for bee abundance (Figure 1). The greatest effect size was attributed to a removal and mulching treatment of the invasive plant Chinese privet (Ligustrum sinense) in a woodland (Hanula \& Horn, 2011). Invasive plant removal had the greatest positive effect on bee abundance $(d=4.84,95 \% \mathrm{Cl} 3.59-6.09$, $p<.0001$, Figure 1). Negative effects of restoration on bee abundance were found in two mowing studies and one grazing study (Figure 1). Bee abundance outcomes were significantly heterogeneous within mowing and grazing categories respectively $(Q=500.41, d f=4, p<.0001$ and $Q=29.32, d f=12, p<.003$, Table 1); other restoration actions did not exhibit significant heterogeneity between individual study results (Table 1 ).

\subsection{Mean effect sizes of restoration and heterogeneity among studies: Bee richness}

With the exception of mowing, all restoration actions had significant positive effects on bee richness (Figure 2). Invasive plant removal had the greatest positive effect on richness $(d=6.38,95 \% \mathrm{Cl} 2.55-10.20, p=.001$, Figure 2), though studies within this category were heterogeneous with respect to their individual effect sizes $(Q=32.81, d f=4, p<.0001$, Table 1). Two individual studies found negative effects on bee richness; Russell, Ikerd, and Droege (2005) reported a negative effect of continuous mowing of powerline strips relative to unmown controls, and Potts et al. (2006) found fewer species of bees in pine forests that had been burned for 10 or more years compared to unburned controls. Grazing, ecological compensation meadows and invasive plant removal groups were all heterogeneous in effect sizes $(Q=11.29, d f=4, p<.02 ; Q=19.02, d f=3$, $p<.001 ; Q=32.81, d f=4, p<.0001$ respectively, Table 1); other restoration actions did not exhibit significant heterogeneity.

\section{3 | Evidence of publication bias}

Asymmetrical funnel plots indicated potential publication bias, specifically that studies with low effect sizes and high standard errors (located in the lower left quadrant) were "missing". Trim and fill analysis estimated zero missing studies for abundance (Figure S1a), but four missing studies for richness (Figure S1b). Inclusion of these missing studies would slightly decrease effect size estimates but still maintain a significant positive effect of restoration on bee richness $(d=0.84$, 95\% Cl [0.31-1.37], $p=.002$ ).

Calculation of Rosenberg's fail-safe number indicated that 1,299 studies with null results for effects of restoration on bee richness would be needed to make the observed effect non-significant ( $p>.05$ ); 3,103 such studies would be needed to make the effect of restoration on bee abundance non-significant. These results provide robust evidence of significant, positive effects of restoration on wild bee abundance and species richness.

\section{4 | DISCUSSION}

Overall, ecological restoration had a positive effect on wild bee abundance and richness across multiple studies, habitat types and geographic regions. With the exception of mowing, all restoration categories had net positive effects on bee abundance and bee richness (Figures 1 and 2). The effects of restoration on bee abundance and richness ranged from nearly 10 -fold increases (Fielder, Landis, \& Arduser, 2012) to non-significant effects; no restoration categories were found to have negative mean effects $(d)$. 
Study description (Authors, year)

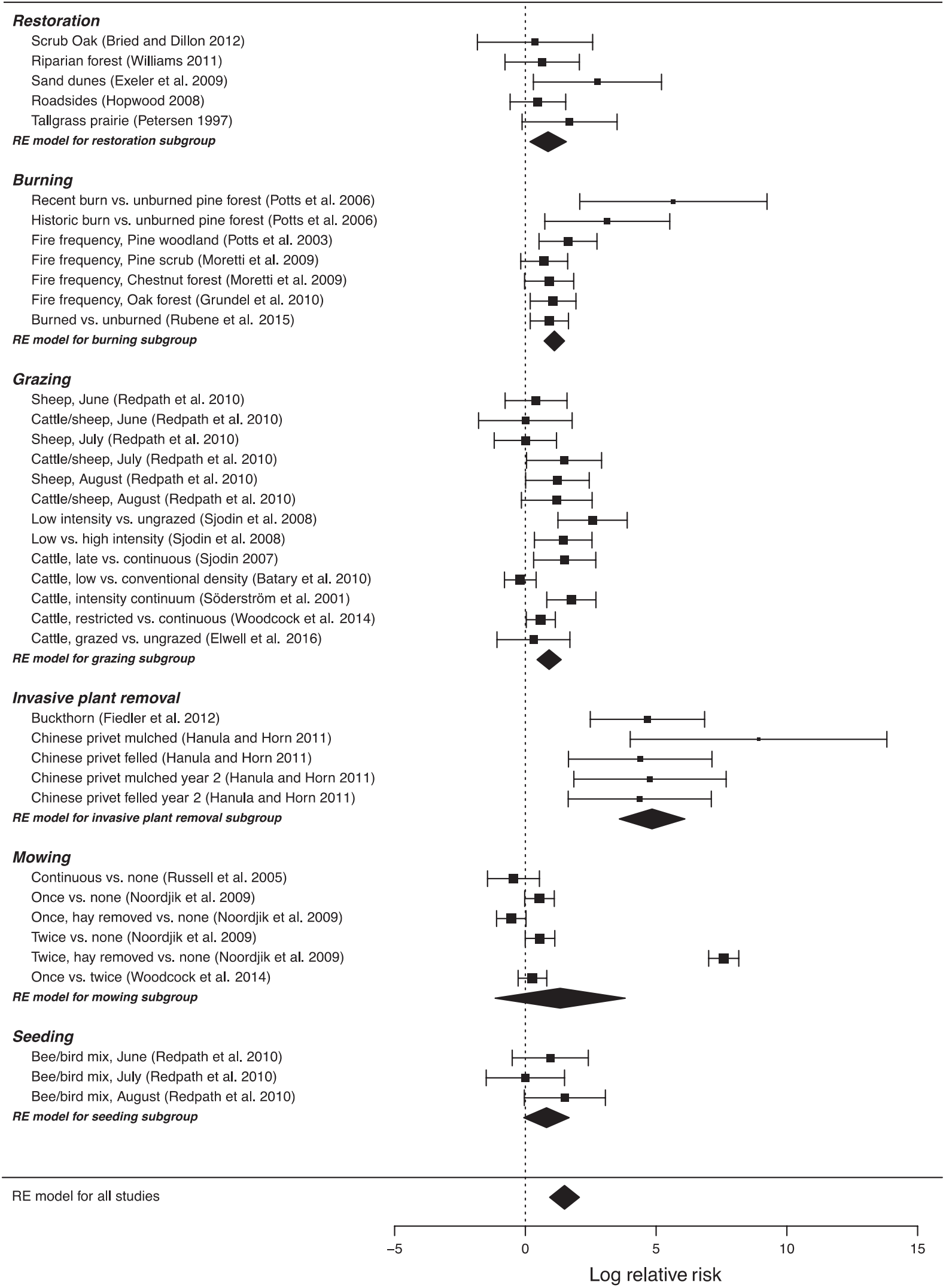

FIGURE 1 The effects of habitat restoration on wild bee abundance. Forest plot showing effect size (Hedge's $d$ ) and $95 \% \mathrm{Cl}$ calculated for each study. The diamond below each category represents the mean effect size for all studies within the group based on a random effects model. The random effects model encompassing all studies from all subgroups is reported at the bottom of the forest plot. The dotted line represents an effect size of zero 


\section{Study description (Authors, year)}

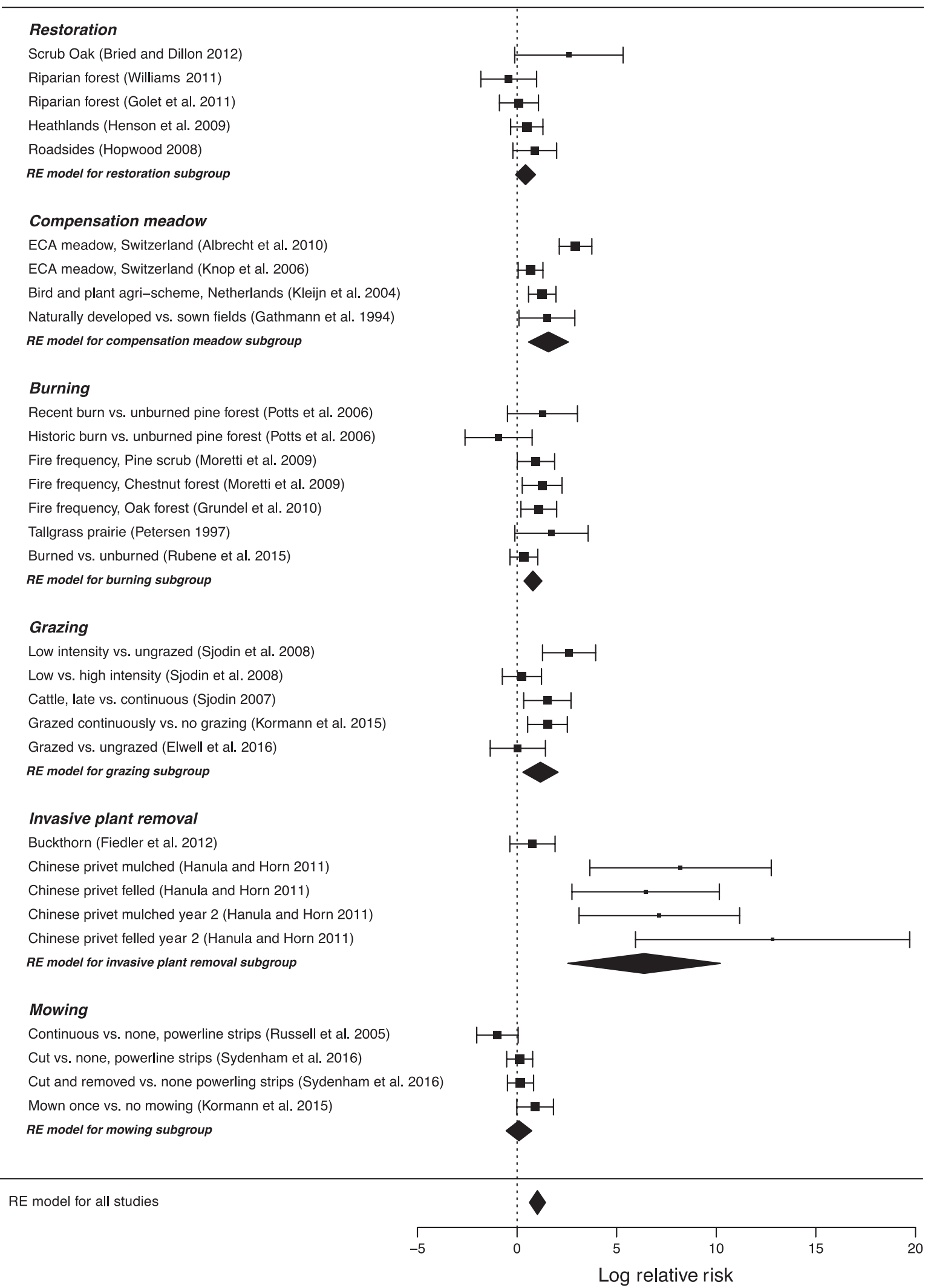

FIGURE 2 The effects of habitat restoration on wild bee richness. Forest plot showing effect size (Hedge's $d$ ) and $95 \% \mathrm{Cl}$ calculated for each study. The diamond below each category represents the mean effect size for all studies within the group based on a random effects model. The random effects model encompassing all studies from all subgroups is reported at the bottom of the forest plot. The dotted line represents an effect size of zero 
Of the 28 studies evaluated in this meta-analysis, only five stated that bee habitat support and conservation were explicit goals of restoration efforts. Restorations tend to be completed with plant community outcomes in mind (Young, 2000), with reference plant communities in high-quality remnant sites as ideal targets. Bees and other pollinators have frequently fallen under the "Field of Dreams" hypothesis: "if we build it, they will come" (Hilderbrand, Watts, \& Randle, 2005), as opposed to having habitats explicitly designed and managed for their needs. If restorations are producing positive effects on wild bee abundance and richness without explicit consideration of their habitat needs, perhaps incorporating bee considerations into restoration planning and design could further increase the benefits provided to bees by ecological restoration, as has been demonstrated in enhanced agricultural systems (Scheper et al., 2013).

Restoration or management techniques could be directly or indirectly affecting bee abundance or richness. For example, grazing and burning commonly employed in grassland restoration can stimulate floral blooming (Packard \& Mutel, 1997), leading to more potential foraging sites for bees. However, techniques such as burning could also directly impact bee abundance and richness via the physical disturbance itself, e.g. by destroying overwintering larvae in stem or twig nests. Overall, as most of the restoration techniques evaluated in this meta-analysis were focused on plant community outcomes, the indirect benefits of a "higher quality" plant community are the most likely drivers of patterns in bee abundance and richness.

\subsection{Identifying gaps and future research opportunities}

Over $90 \%$ of the studies that fit our selection criteria were performed in North America or Europe, which also means the restoration techniques examined here may not be representative of global restoration efforts. Studies tended to be from grasslands (e.g. prairie and savanna) and forests, on lands that had been heavily impacted by invasive plant species, were former agricultural fields, or were being used as "working" grasslands for grazing or hay production. As demonstrated by Moretti et al. (2009), the response of bees to restoration actions cannot be assumed to be the same across habitat types or regions. Though a strength of a meta-analytical approach is to synthesize effect sizes across studies, this approach is sensitive to the size and diversity of the pool of available studies. Further research addressing bee responses to restoration in more parts of the world, in more habitat types and with respect to more management actions is needed to gain a deeper understanding of the benefits of restoration to bees.

It is important to note that data on community composition of bees were not available for most studies, thus we were unable to perform analyses of how different types of bees responded to restoration (e.g. cavity-dwelling vs. soil-dwelling bees). For example, evidence from agricultural systems suggests habitat enhancements promote increased functional redundancy in bee communities (Woodcock, Collin Harrower, et al., 2014). Williams et al. (2010) found that bees' responses to disturbance were mediated by their traits, and Tonietto,
Ascher, and Larkin (2017) found that bee functional trait composition varied among restorations of different age. As species lists are more commonly published and archived, functional analysis of wild bee species' responses to restoration will become possible.

\subsection{Conservation implications and recommendations for management}

Habitat restoration can help to counteract habitat loss, the greatest threat to wild bee abundance and richness (Winfree et al., 2009). Here, we document an overall positive effect of habitat restoration on wild bee abundance and richness, even when restoration planning and goal setting did not explicitly consider the habitat needs of wild bees. This is important, considering a recent survey found that only $11 \%$ of grassland managers in the Midwestern USA considered the habitat needs of wild bees during the restoration process (Harmon-Threatt \& Chin, 2016).

To better support wild pollinators, recent studies have documented the importance of designing restoration seed mixes for forbs with overlapping bloom times and multiple floral morphologies (Harmon-Threatt \& Hendrix, 2014; Havens \& Vitt, 2016; M'Gonigle et al., 2016). For many localities, pollinator-friendly plant species lists have already been developed (e.g. Mader \& Shepard, 2010) for use in managed lands or residential gardens. Our findings raise the possibility that still greater conservation results for bees could be achieved were land managers to take the additional step of incorporating bee foraging and nesting needs as design considerations in restoration planning (e.g. Shepherd, 2002; Shepherd, Vaughn, \& Black, 2008; Shepherd et al., 2003; Vaughan \& Skinner, 2008).

\section{ACKNOWLEDGEMENTS}

Funding to R.K.T. was provided by the Northwestern University Presidential Fellowship, Plant Biology and Conservation graduate program grants through Northwestern University and the Chicago Botanic Garden, the Garden Club of America Fellowship in Ecological Restoration and the Prairie Biotic Research Grant. We thank Steve Hendrix, Eric Lonsdorf, the Larkin Laboratory, Ben Woodcock, one anonymous reviewer and the editor, whose comments greatly improved the manuscript.

\section{AUTHORS' CONTRIBUTIONS}

R.K.T. and D.J.L. conceived the study. R.K.T. collected and analysed data and drafted the article. R.K.T. and D.J.L. revised the article and gave final approval for publication.

\section{DATA ACCESSIBILITY}

All data used in this manuscript are present in the manuscript and its supporting information, and are available from the Dryad Digital Repository https://doi.org/10.5061/dryad.q1791 (Tonietto \& Larkin, 2017). 


\section{ORCID}

\section{Rebecca K. Tonietto (iD http://orcid.org/0000-0002-8336-674X}

\section{REFERENCES}

Albrecht, M., Schmid, B., Obrist, M. K., Schüpach, B., \& Kleijn, D. (2010). Effects of ecological compensation meadows on arthropod diversity in adjacent intensively managed grassland. Biological Conservation, 143, 642-649.

Batáry, P., Báldi, A., Sárospataki, M., Kohler, F., Verhulst, J., Knop, E., ... Kleijn, D. (2010). Effect of conservation management on bees and insect-pollinated grassland plant communities in three European countries. Agriculture, Ecosystems \& Environment, 136, 35-39.

Bried, J. T., \& Dillon, A. M. (2012). Bee diversity in scrub oak patches 2 years after mow and herbicide treatment. Insect Conservation and Diversity, 5, 237-243.

Buchmann, S. L., \& Nabhan, G. P. (1996). The forgotten pollinators. Covelo, CA: Island Press.

Cameron, S. A., Lozier, J. D., Strange, J. P., Koch, J. B., Cordes, N., Solter, L. F., \& Griswold, T. (2011). Patterns of widespread decline in North American bumble bees. Proceedings of the National Academy of Sciences of the United States of America, 108, 662-667.

Clarviate Analytics. (2015). Web of science. New York, NY: Thomson Reuters.

Dicks, L. V., Showler, D. A., \& Sutherland, W. J. (2010). Bee conservation: Evidence for the effects of interventions. Exeter: Pelagic Publishing.

Dostálek, J., \& Frantík, T. (2008). Dry grassland plant diversity conservation using low-intensity sheep and goat grazing management: Case study in Prague (Czech Republic). Biodiversity and Conservation, 17, 1439-1454.

Elwell, S. L., Griswold, T., \& Elle, E. (2016). Habitat type plays a greater role than livestock grazing in structuring shrubsteppe plant-pollinator communities. Journal of Insect Conservation, 20, 515-525.

Fielder, A. K., Landis, D. A., \& Arduser, M. (2012). Rapid shift in pollinator communities following invasive species removal. Restoration Ecology, 20, 593-602.

Frankie, G., Thorp, R. W., Hernandez, J., Rizzardi, M., Ertter, B., Pawelek, J. C., ... Wojcik, V. A. (2009). Native bees are a rich natural resource in urban California gardens. California Agriculture, 63, 113-120.

Gathmann, A., Greiler, H. J., \& Tscharntke, T. (1994). Trap-nesting bees and wasps colonizing set-aside fields: Succession and body size, management by cutting and sowing. Oecologia, 98, 8-14.

Golet, G. H., Gardali, T., Hunt, J. W., Koening, D. A., \& Williams, N. M. (2011). Temporal and taxonomic variability in response of fauna to riparian restoration. Restoration Ecology, 19, 126-135.

Grixti, J. C., Wong, L. T., Cameron, S. A., \& Favret, C. (2009). Decline of bumble bees (Bombus) in the North American Midwest. Biological Conservation, 142, 75-84.

Grundel, R., Jean, R. P., Frohnapple, K. J., Glowacki, G. A., Scott, P. E., \& Pavlovic, N. B. (2010). Floral and nesting resources, habitat structure, and fire influence bee distribution across an open-forest gradient. Ecological Applications, 20, 1678-1692.

Haaland, C., Naisbit, R. E., \& Bersier, L. (2011). Sown wildflower strips for insect conservation: A review. Insect Conservation and Diversity, 4, 60-80.

Hall, D. M., Camilo, G. D., Tonietto, R. K., Ollerton, J., Ahrné, K., Arduser, M., ... Threlfall, C. (2016). The city as a refuge for insect pollinators. Conservation Biology, 31, 24-29.

Hanula, J. L., \& Horn, S. (2011). Removing an invasive shrub (Chinese privet) increases native bee diversity and abundance in riparian forests of the southeastern United States. Insect Conservation and Diversity, 4, 275-283.

Harmon-Threatt, A. N., \& Chin, K. (2016). Common methods for tallgrass prairie restoration and their potential effects on bee diversity. Natural Areas Journal, 36, 400-411.
Harmon-Threatt, A. N., \& Hendrix, S. D. (2014). Prairie restorations and bees: The potential ability of seed mixes to foster native bee communities. Basic and Applied Ecology, 16, 64-72.

Havens, K., \& Vitt, P. (2016). The importance of phenological diversity in seed mixes for pollinator restoration. Natural Areas Journal, 36, 531-537.

Hayes, G. F., \& Holl, K. D. (2003). Cattle grazing impacts on annual forbs and vegetation composition of mesic grasslands in California. Conservation Biology, 17, 1694-1702.

Hedges, L. V., \& Olkin, I. (1985). Statistical methods for meta-analysis. Orlando, FL: Academic Press.

Henson, K. S. E., Craze, P. G., \& Memmott, J. (2009). The restoration of parasites, parasitoids, and pathogens to heathland communities. Ecology, 90, 1840-1851.

Hernandez, J. L., Frankie, G. W., \& Thorp, R. (2009). Ecology of urban bees: A review of current knowledge and directions for future study. Cities and the Environment, 2. Article 3.

Hilderbrand, R. H., Watts, A. C., \& Randle, A. M. (2005). The myths of restoration ecology. Ecology and Society, https://doi.org/10.5751/ ES-01277-100119.

Hopwood, J. L. (2008). The contribution of roadside grassland restorations to native bee conservation. Biological Conservation, 141, 2632-2640.

Kleijn, D., Berendse, F., Smit, R., Gilissen, N., Smit, J., Brak, B., \& Groeneveld, R. (2004). Ecological effectiveness of agri-environment schemes in different agricultural landscapes in the Netherlands. Conservation Biology, 18, 775-786.

Knop, E., Kleijn, D., Herzog, F., \& Schmid, B. (2006). Effectiveness of the Swiss agri-environment scheme in promoting biodiversity. Journal of Applied Ecology, 43, 120-127.

Koricheva, J., Gurecitch, J., \& Mengersen, K. (Eds.) (2013). The handbook of meta-analysis in ecology and evolution. Princeton and Oxford: Princeton University Press.

Kormann, U., Rosch, V., Batary, P., Tscharntke, T., Orci, K. M., Samu, F., \& Scherber, C. (2015). Local and landscape management drive traitmediated biodiversity of nine taxa on small grassland fragments. Diversity and Distributions, 21, 1204-1217.

Maclvor, J. S., \& Packer, L. (2015). 'Bee Hotels' as tools for native pollinator conservation: A premature verdict? PLoS ONE, 10, e0122126.

Mader, E., \& Shepard, M. (2010). Upper midwest plants for native bees. Page 2 invertebrate conservation fact sheet. The Xerces Society, Portland, OR.

M'Gonigle, L. K., Williams, N. M., Lonsdorf, E., \& Kremen, C. (2016). A tool for selecting plants when restoring habitat for pollinators. Conservation Letters, 10, 105-111.

Michener, C. D. (2000). The bees of the world. Baltimore, MA: The Johns Hopkins University Press.

Montoya, D., Rogers, L., \& Memmott, J. (2012). Emerging perspectives in the restoration of biodiversity-based ecosystem services. Trends in Ecology \& Evolution, 27, 666-672.

Moretti, M., de Bello, F., Roberts, S. P. M., \& Potts, S. G. (2009). Taxonomical vs. functional responses of bee communities to fire in two contrasting climatic regions. Journal of Animal Ecology, 78, 98-108.

Morrison, L. W. (2016). Observer error in vegetation surveys: A review. Journal of Plant Ecology, 4, 367-379.

National Research Council. (2007). The status of pollinators in North America. Washington, DC: The National Academies Press.

Noordjik, J., Delille, K., Schaffers, A. P., \& Sýkora, K. V. (2009). Optimizing grassland management for flower-visiting insects in roadside verges. Biological Conservation, 142, 2097-2103.

Packard, S., \& Mutel, F. C. (1997). The tallgrass restoration handbook: For prairies, savannas, and woodlands. Washington, DC: Society for Ecological Restoration by Island Press.

Pawelek, J. C., Frankie, G. W., Thorp, R. W., \& Przybyiski, M. (2009). Modification of a community garden to attract native bee pollinators in urban San Louis Obispo, California. Cities and the Environment, 2. Article 7. 
Petersen, C. E. (1997). Bee visitors of four reconstructed tallgrass prairies in northeastern Illinois. In Fifteenth North American prairie conference, pp. 200-206. Bend, OR USA: Natural Areas Association.

Potts, S. G., Petanidou, T., Roberts, S., O'Toole, C., Hulbert, A., \& Wilmer, P. (2006). Plant-pollinator biodiversity and pollination services in a complex Mediterranean landscape. Biological Conservation, 129, 519-529.

Potts, S. G., Vulliamy, B., Dafni, A., Ne'eman, G., O'Toole, C., Roberts, S., \& Willmer, P. (2003). Response of plant-pollinator communities to fire: Changes in diversity, abundance and floral reward structure. Oikos, 101, 102-113.

Pywell, R. F., Heard, M. S., Bradbury, R. B., Hinsley, S., Nowakowski, M., Walker, K. J., \& Bullcok, J. M. (2012). Wildlife-friendly farming benefits rare birds, bees and plants. Biology Letters, 8, 772-775.

Pywell, R. F., Warman, E. A., Carvell, C., Sparks, T. H., Dicks, L. V., Bennett, D., ... Sherwood, A. (2005). Providing foraging resources for bumblebees in intensively farmed landscapes. Biological Conservation, 121, 479-494.

R Development Core Team. (2015). R: A language and environment for statistical computing. Vienna, Austria: R Foundation for Statistical Computing. Retrieved from http://www.R-project.org .

Redpath, N., Osgathorpe, L. M., Park, K., \& Goulson, D. (2010). Crofting and bumblebee conservation: The impact of land management practices on bumblebee populations in northwest Scotland. Biological Conservation, 143, 492-500.

Rohatgi, A. (2015). WebPlotDigitizer . Version 3.12. Retrieved from http:// arohatgi.info/WebPlotDigitizer.

Rosenberg, M. S. (2005). The file-drawer problem revisited: A general weighted method for calculating fail-safe numbers in meta-analysis. Evolution, 59, 464-468.

Rubene, D., Schroeder, M., \& Ranius, T. (2015). Diversity patterns of wild bees and wasps in managed boreal forests: Effects of spatial structure, local habitat and surrounding landscape. Biological Conservation, 184, 201-208.

Russell, K. N., Ikerd, H., \& Droege, S. (2005). The potential conservation value of unmown powerline strips for native bees. Biological Conservation, 124, 133-148.

Scheper, J., Holzchuh, A., Kuussaari, M., Potts, S. G., Rundlöf, M., Smith, H. G., \& Kleijn, D. (2013). Environmental factors driving the effectiveness of European agri-environmental measures in mitigating pollinator loss - A meta-analysis. Ecology Letters, 16, 912-920.

Schmidt, F. L., \& Hunter, J. E. (2015). Methods of meta-analysis: Correcting error and bias in research findings (3rd edn). Thousand Oaks, CA: Sage Publications.

SER (2004). The SER international primer on ecological restoration. Tucson, AZ: Society for Ecological Restoration International.

Severns, P. (2004). Creating bare ground increases presence of native pollinators in Kincaid's lupine seeding plots (Oregon). Ecological Restoration, 22, 234-235.

Shepherd, M. (2002). Making room for native pollinators: How to create habitat for pollinator insects on golf courses. Portland, OR: The Xerces Society.

Shepherd, M., Buchmann, S. L., Vaughn, M., \& Black, S. H. (2003). Pollinator conservation handbook: A guide to understanding, protecting, and providing habitat for native pollinator insects. Portland, OR: The Xerces Society.

Shepherd, M., Vaughn, M., \& Black, S. H. (2008). Pollinator-friendly parks: How to enhance parks, gardens, and other greenspaces for native pollinator insects (2nd edn.). Portland, OR: The Xerces Society.

Sjodin, N. E. (2007). Pollinator behavioural responses to grazing intensity. Biodiversity and Conservation, 16, 2103-2121.
Sjodin, N. E., Bengtsson, J., \& Ekbom, B. (2008). The influence of grazing intensity and landscape composition on the diversity and abundance of flower-visiting insects. Journal of Applied Ecology, 45, 763-772.

Söderström, B., Svensson, B., Vessby, K., \& Glimskär, A. (2001). Plants, insects and birds in semi-natural pastures in relation to local habitat and landscape factors. Biodiversity and Conservation, 10, 1839-1863.

Sydenham, M. A. K., Moe, S. R., Stanescu-Yadav, D. N., Totland, O., \& Eldegard, K. (2016). The effects of habitat management on the species, phylogenetic and functional diversity of bees are modified by the environmental context. Ecology and Evolution, 6, 961-973.

Tonietto, R. K., Ascher, J. S., \& Larkin, D. J. (2017). Bee communities along a prairie restoration chronosequence: Similar abundance and diversity, distinct composition. Ecological Applications, 27, 705-717

Tonietto, R. K., \& Larkin, D. J. (2017). Data from: Habitat restoration benefits wild bees: A meta-analysis. Dryad Digital Repository, https://doi. org/10.5061/dryad.q1791

Vaughan, M., \& Skinner, M. (2008). Using farm bill programs for pollinator conservation. Page 12 in N. USDA. The Xerces Society, San Francisco State University, editor.

Viechtbauer, W. (2010). Conducting meta-analyses in R with the metafor package. Journal of Statistical Software, 36, 1-48.

Wesserling, J., \& Tscharntke, T. (1995). Habitat selection of bees and digger wasps - experimental management of plots. Mitteilungen der Deutschen Gesellschaft für Allgemeine und Angewandte Entomologie, 9, 697-701.

Williams, N. M. (2011). Restoration of nontarget species: Bee communities and pollination function in riparian forests. Restoration Ecology, 19, 450-459.

Williams, N., Crone, E. E., Roulston, T. A. H., Minckley, R. L., Packer, L., \& Potts, S. G. (2010). Ecological and life-history traits predict bee species responses to environmental disturbances. Biological Conservation, 143, 2280-2291.

Winfree, R., Aguilar, R., Vasquez, D. P., LeBuhn, G., \& Aizen, M. A. (2009). A meta-analysis of bees' responses to anthropogenic disturbance. Ecology, 90, 2068-2076.

Woodcock, B. A., Harrower, C., Redhead, J., Edwards, M., Vanbergen, A. J., Heard, M. S., ... Pywell, R. F. (2014). National patterns of functional diversity and redundancy in predatory ground beetles and bees associated with key UK arable crops. Journal of Applied Ecology, 51, 142-151.

Woodcock, B. A., Savage, J., Bullock, J. M., Nowakowski, M., Orr, R., Tallowin, J. R. B., \& Pywell, R. F. (2014). Enhancing floral resources for pollinators in productive agricultural grasslands. Biological Conservation, $171,44-51$.

Young, T. P. (2000). Restoration ecology and conservation biology. Biological Conservation, 92, 73-83.

\section{SUPPORTING INFORMATION}

Additional Supporting Information may be found online in the supporting information tab for this article.

How to cite this article: Tonietto RK, Larkin DJ. Habitat restoration benefits wild bees: A meta-analysis. J Appl Ecol. 2018;55:582-590. https://doi.org/10.1111/1365-2664.13012 